\title{
Study of fetomaternal outcome in cases of placenta previa at tertiary care hospital
}

\author{
Parul T. Shah, Fiza Z. Saiyed*, Kruti J. Deliwala, Priya Dhameliya
}

Department of Obstetrics and Gynecology, SVP Hospital and NHL Medical College, Ahmedabad, Gujarat, India

Received: 30 May 2020

Accepted: 06 July 2020

*Correspondence:

Dr. Fiza Z. Saiyed,

E-mail: fizasaiyed3194@gmail.com

Copyright: (C) the author(s), publisher and licensee Medip Academy. This is an open-access article distributed under the terms of the Creative Commons Attribution Non-Commercial License, which permits unrestricted non-commercial use, distribution, and reproduction in any medium, provided the original work is properly cited.

\begin{abstract}
Background: Placenta previa is defined as placenta implanted partially or completely in the lower uterine segment. It contributes upto $30 \%$ of the cases the antepartum hemorrhage. This catastrophic complication not only poses a risk to the fetus but also endangers the mother's life. The objective of the study was to determine the incidence and risk factors, obstetric management, maternal mortality and morbidity and perinatal outcome in women presenting with placenta previa.

Methods: It is the prospective study of 50 cases carried out to study the maternal and perinatal outcome in cases of placenta previa in tertiary care hospital. This study included antenatal patient diagnosed as placenta previa by ultrasound $>28$ weeks to full term pregnancy. This data was compiled and analyzed for maternal and neonatal outcome.

Results: In the present study, the incidence of placenta previa is $0.8 \%$ among which $42 \%$ of cases having age group of 25-29 years and 72\% cases are multigravida. In this study $60 \%$ cases have major degree of placenta previa and $66 \%$ cases have previous history of caesarean section. Out of total cases $96 \%$ cases delivered by caesarean section and $4 \%$ had Normal delivery. NICU admission in the study is 28 babies i.e. $56 \%$. There is no maternal mortality seen in the present study.

Conclusions: Risk factors that increase the cases of placenta previa are multiparity, previous caesarean section, previous abortion. Placenta previa is major risk factor for adverse maternal and perinatal outcome. Good antenatal care, availability of emergency obstetrics services with senior obstetricians, blood bank facility, ICU care and NICU services can improve maternal and neonatal outcome in high risk cases.
\end{abstract}

Keywords: Maternal mortality, Placenta previa, Postpartum hemorrhage, Previous caesarean delivery

\section{INTRODUCTION}

Placenta previa is defined as when the placenta is partly or completely implanted in the lower uterine segment, overlying or approaching internal cervical os. ${ }^{1}$ Around one third of the all cases from antepartum hemorrhage belongs to placenta previa. ${ }^{2}$ Obstetric hemorrhage is one of the most common causes of maternal morbidity and mortality worldwide. Incidence of placenta previa averages $0.3 \%-0.5 \%$ or 1 case in 300 to 400 deliveries. $^{3}$
There are four types of placenta previa depending upon the degree of extension of placenta in lower segment. i.e., Type 1 - low lying, Type 2 - marginal, Type 3 incomplete or partial central and Type 4 - complete or central.

Clinically they are divided in to 2 grade that are mention below:

Mild degree: Type 1 and Type 2 anterior. 
Major degree: Type 2 posterior, Type 3 and Type 4.

Posterior placenta previa is slightly more common and more dangerous, because it discourages engagement of the head more often and the placenta is likely to be compressed in labour impairing placental perfusion.nSeveral factors that are associated with placenta previa are advancing maternal age, multiparity, previous abortions, previous history of placenta previa with rising incidence of prior caesarean delivery increase the likelihood of placeta previa by $22 \%{ }^{4}$ It can be associated with placenta increta, accreta or percreta. The simple, most precise and safe method of placental localization is transabdominal sonography. ${ }^{5}$

Usually patients of placenta previa presents with painless, causeless bleeding in late second trimester and thereafter. In some patients, bleeding is excessive and lead to maternal shock and becomes a serious condition to manage. So, there is increased incidence of operative interventions and also postpartum hemorrhage. This leading to increased risk of maternal morbidity and mortality. ${ }^{6}$ Preterm delivery is the major cause of perinatal death even with expectant management of placenta previa. ${ }^{7}$ Management of placenta previa depends on presentation, gestational age and degree of previa. ${ }^{6-10}$ When mothers life is not at risk, expectant management will improve the outcome of fetus. ${ }^{11}$

Objective of this study is to study the demographic features, obstetric risk factors and management, and perinatal outcome in women presenting with placenta previa.

\section{METHODS}

This is a prospective study of 50 cases of placenta previa admitted during the period of February 2019 to February 2020 at study tertiary care hospital, Ahmedabad, Gujarat, India.

\section{Inclusion criteria}

- This study included all patients that diagnosed as placenta previa by ultrasonography irrespective of age, parity, socioeconomic status, demographic status with gestational age more than or equal to 28 weeks

- Emergency cases and registered cases both are included

- Some patients came with the complain of vaginal bleeding at full term.

- While some are diagnosed in antenatal period during routine sonography examination.

\section{Exclusion criteria}

- $\quad$ The cases which having gestational age below 28 weeks and other causes of antepartum hemorrhage are excluded.
Detailed study was carried out including patient age, parity, gestational age and clinical features, detailed history of current pregnancy and previous pregnancies, period of gestation at which placenta previa was diagnosed, history of warning bleeding etc are documented. Duration of hospitalization, need for blood transfusion, period of gestation at delivery, mode of delivery (vaginal or caesarean), methods to prevent or to stop bleeding like cervico-isthmic stich, uterine artery ligation, hysterectomy and need for ICU admissions are noted. Study of maternal mortality and morbidity was done with respect to development of hypovolemic shock, DIC, anemia, acute kidney injury, septicaemia and maternal deaths. Data were also collected regarding delivery (presentation of fetus, mode of delivery and gestational age at delivery), neonatal (birth weight, NICU admission).

\section{RESULTS}

In present study 50 cases of placenta previa were studied regarding the presentation of cases, the duration of clinical sign to appear, the maternal and perinatal outcome.

Table 1: Age distribution among the cases of placenta previa.

\begin{tabular}{|lll|}
\hline Age & No. of cases & percentage \\
\hline$<20$ years & 5 & $19 \%$ \\
\hline 20-24 years & 17 & $35 \%$ \\
\hline 25-29 years & 21 & $42 \%$ \\
\hline$>30$ years & 7 & $14 \%$ \\
\hline Total & 50 & $100 \%$ \\
\hline
\end{tabular}

Table 2: Parity and risk of having placenta previa.

\begin{tabular}{|lll|}
\hline Parity & No. of cases & Percentage \\
\hline $0-1$ & 14 & $28 \%$ \\
\hline $2-4$ & 28 & $56 \%$ \\
\hline$>5$ & 8 & $16 \%$ \\
\hline Total & 50 & $100 \%$ \\
\hline
\end{tabular}

Table 3: Types of placenta previa on ultrasonography.

\begin{tabular}{|lll|}
\hline $\begin{array}{l}\text { Type of placenta } \\
\text { previa }\end{array}$ & $\begin{array}{l}\text { No. of cases in } \\
\text { study }\end{array}$ & Percentage \\
\hline Type 1 low lying & 12 & $24 \%$ \\
\hline Type 2 marginal & 8 & $16 \%$ \\
\hline Type 3 partial & 21 & $42 \%$ \\
\hline Type 4 central & 9 & $18 \%$ \\
\hline Total & 50 & 100 \\
\hline
\end{tabular}

The result obtained from the study are analyzed statistically.

The total delivery conducted in the hospital during that period was 7250 . 
So, the incidence of placenta previa in present study was $0.8 \%$.

As in the present study of 50 cases there were 32 patients were registered patient of the study institute and 18 patients were emergency patient as they were referred from other facilities.

The maximum number of patients in the study group are seen in the age group of 25-29 years (Table 1).

Multiparous women are at higher risk of having placenta previa than primi.

Diagnosis of type of placenta previa by ultrasonography showed the result that out of 50 cases 21 cases $(42 \%)$ having placenta that partially cover internal os. $52 \%$ cases diagnosed during antenatal visits and $48 \%$ cases came with complain of bleeding per vagina and admitted in hospital. They were first given conservative management and if bleeding was persistent than termination of pregnancy was planned.

Most common etiological factor associated with placenta previa is previous caesarean section and in the study $66 \%$ cases are associated with that.

Table 4: Etiological factors associated with placenta previa.

\begin{tabular}{|lll|}
\hline Risk factor & $\begin{array}{l}\text { No. of } \\
\text { cases }\end{array}$ & Percentage \\
\hline Previous CS & 11 & $22 \%$ \\
\hline Previous 2CS & 22 & $44 \%$ \\
\hline Previous D and E & 9 & $18 \%$ \\
\hline Previous history of previa & 3 & $6 \%$ \\
\hline
\end{tabular}

\section{Mode of delivery and management}

Out of 50 patient of placenta previa, 48 patients delivered by caesarean section and 2 patients delivered by vaginal route having Type 1 - low lying placenta previa. There were total 48 caesarean sections in which 16 cases were taken as emergency as presented with bleeding whereas, the rest were planned procedure.

Table 5: Management for haemostasis.

\begin{tabular}{|ll|}
\hline Procedures & $\begin{array}{l}\text { No. of } \\
\text { cases }\end{array}$ \\
\hline Bilateral Uterine artery ligation & 21 \\
\hline $\begin{array}{l}\text { Hemostatic sutures over the uterus or on } \\
\text { placental bed }\end{array}$ & 9 \\
\hline Intra-uterine packing & 5 \\
\hline Obstetric hysterectomy & 3 \\
\hline
\end{tabular}

Placenta previa is associated with more chances of postpartum hemorrhage because of improper retraction of lower uterine segment and may be associated with accreta and percreta. In present study there were 38 cases in which extra surgical steps needed to control bleeding that discussed in Table 5.

Table 6: Maternal complication seen during management of placenta previa.

\begin{tabular}{|lll|}
\hline Complication & $\begin{array}{l}\text { No. of } \\
\text { cases }\end{array}$ & Percentage \\
\hline Postpartum hemorrhage & 16 & $32 \%$ \\
\hline Hypovolemic shock & 8 & $16 \%$ \\
\hline Renal failure & 2 & $4 \%$ \\
\hline $\begin{array}{l}\text { Disseminated intravascular } \\
\text { coagulation (DIC) }\end{array}$ & 3 & $6 \%$ \\
\hline Septicaemia & 3 & $6 \%$ \\
\hline
\end{tabular}

In the present study 32 patients accounted $64 \%$ of total cases were required blood transfusion whereas, other cases were not required any blood components.

Six out of 50 patients accounted $12 \%$ of total cases were required ICU admission as complication occurred in that.

In the present study, no maternal mortality found. Authors have analysed the neonatal outcome and factors responsible for poor neonatal outcome that discussed in Table 7.

Table 7: Neonatal outcome.

\begin{tabular}{|lll|}
\hline Factors & $\begin{array}{l}\text { No. of } \\
\text { cases }\end{array}$ & Percentage \\
\hline $\begin{array}{l}\text { Gestational age (maturity) } \\
28-32 \text { weeks }\end{array}$ & 8 & $16 \%$ \\
\hline $33-36$ weeks & 25 & $50 \%$ \\
\hline$>37$ weeks & 17 & $24 \%$ \\
\hline Birth weight & & \\
\hline$<1.5 \mathrm{~kg}$ & 6 & $12 \%$ \\
\hline $1.5-2.4 \mathrm{~kg}$ & 22 & $36 \%$ \\
\hline $2.5-3.4 \mathrm{~kg}$ & 18 & $44 \%$ \\
\hline$>3.5 \mathrm{~kg}$ & 4 & $8 \%$ \\
\hline NICU admission & 28 & $56 \%$ \\
\hline Preterm birth & 15 & $30 \%$ \\
\hline Still birth & 1 & $2 \%$ \\
\hline
\end{tabular}

\section{DISCUSSION}

Pregnancy having placenta previa is most dangerous condition because it is associated with adverse maternal and perinatal outcome. The majority of the cases seen in age group of 25-29 years that is $42 \%$ of total cases comparable to study of Mayerkar S.

Highest incidence of placenta previa seen in multiparous group. In this study $72 \%$ cases of previa seen in multiparous patients which is comparable with study of William M. Previous caesarean section is most important risk factor of placenta previa. In this study $66 \%$ cases 
associated with previous caesarean section and $18 \%$ cases having history of prior $\mathrm{D}$ and $\mathrm{E}$ that become major etiological factor of placenta previa. In the study of Ananth CV et al, advancing maternal age, multiparity, previous caesarean section and previous abortion, smocking habits all are confirmed that increased risk of placenta previa.

In the present study $96 \%$ cases delivered by caesarean section. High rate of caesarean delivery in this study attributed to high number of referred cases and cases seen with type 3 and type 4 placenta previa. Only 2 patients delivered by vaginal route they are having typec1 placenta previa.

The major cause of mortality and morbidity in placenta previa are hemorrhage both antepartum and postpartum. In the present study $44 \%$ patient developed postpartum hemorrhage in which 9 cases required hemostatic sutures over uterus and 3 cases undergone hysterectomy. In the present study $16 \%$ patient developed hypovolemic shock and required blood transfusion and $2 \%$ developed renal failure and 3\% developed DIC and 4\% developed septicemia.

It was observed in the study that $76 \%$ of patients with placenta previa delivered before 38 weeks of pregnancy showing high incidence of prematurity which co-relate that higher incidence of emergency cases came to the hospital with bleeding per vagina and required termination. $56 \%$ of newborn admitted to the neonatal intensive care unit (NICU). Morbidity was more marked in $16 \%$ of cases whose gestation age were below 32 weeks. Major cause of low birth weight in placenta previa was because of preterm delivery and lesser extend to fetal growth restriction. According to RCOG guidelines elective delivery by caesarean section in asymptomatic women is not recommended before 38 weeks of gestation for placenta previa. ${ }^{12}$

The increased use of caesarean section preceded by expectant treatment in the study reduced maternal mortality to nil and fetal mortality to $<10 \%$.

\section{CONCLUSION}

Placenta previa is one of the most serious obstetrics emergencies, risk factor for placenta previa are multiparity, previous caesarean section, and previous abortion leading to serious maternal complication which adversely affect fetomaternal outcome. Early diagnosis of placenta previa by transabdominal sonography, regular antenatal check-ups, correction of anemia, educating the patient about her risk of developing complications at the time of delivery can prevent patient from mortality.
Delivery at tertiary care center with well-equipped blood bank, senior obstetrician, obstetric ICU and NICU facilities will definitely help in reducing maternal and fetal morbidities and improving fetomaternal outcome.

\section{ACKNOWLEDGMENTS}

Authors would like to thank all faculties colleague, post graduate residents and labour room staff for their support.

\section{Funding: No funding sources \\ Conflict of interest: None declared}

Ethical approval: The study was approved by the Institutional Ethics Committee

\section{REFERENCES}

1. Elsayes KM, Trout AT, Friedkin AM, Liu PS, Bude RO, Platt JF, et al. Imaging of the placenta: a multimodality pictorial review. Radiograph. 2009;29(5):1371-91.

2. Williams textbook of obstetrics. $24^{\text {th }}$ ed, obstetrical hemorrhage; 2014: 800.

3. Cunningham F, Williams J. Williams obstetrícia. $24^{\text {th }}$ ed. México, McGraw-Hill Education; 2014: 801.

4. Frederiksen MC, Glassenberg R, Stika CS. Placenta previa: a 22-year analysis. Am J Obstet Gynecol. 2009; $180: 1432$.

5. Cunningham FG, Leveno KJ, Bloom SL, Haulh JC, Gilstrap LC, Wenstrom KD. Editors. Obstetric haemorrhage. In: Williams Textbook of Obstetrics, $22^{\text {nd }}$ ed. New York: McGraw-Hill; 2010: 809-823.

6. James DK, Steer PJ, Weiner CP, Gonic B, editors. Bleeding in Late Pregnancy, In: Text book of high risk pregnancy management options $3^{\text {rd }}$ ed. Saunders; 2010: 1259-1266

7. Salihu HM, Li Q, Rouse DJ. Placenta previa: neonatal deaths after live births in the United States. Am J Obstet Gynecol. 2003;188:1305-8.

8. Cotton D, Read JA, Paul RH, Quilligan EJ. The conservative aggressive management of placenta previa. Am J Obstet Gynecol. 1999; 137:687-95.

9. Kaseem GA, Azlahrani AA. Maternal and neonatal outcomes of placenta previa and placenta acreta three years of experience with a two- consultant approach. Int $\mathbf{J}$ Womens Health. 2013;5:803-10.

10. Onwere C, Urganci IG, Cromwell DA, Mahmood TA, Templeton A, Jan $\mathrm{H}$, et al. Maternal morbidity associated with placenta previa among women who had elective caesarean section. European J Obst Gyn Repro Bio. 2012;159:62-6.

11. Rosenberg T, Pariente G, Sergienko R, Wiznitzer A, Sheiner W. Critical analysis of risk factors and outcome in placenta previa. Arch Gynecol Obstet. 2011;284:47-51.

12. No GT. Placenta praevia, placenta praevia accreta and vasa praevia: diagnosis and management. London: RCOG; 2011: 1-26.

Cite this article as: Shah PT, Saiyed FZ, Deliwala KJ, Dhameliya P. Study of fetomaternal outcome in cases of placenta previa at tertiary care hospital. Int J Reprod Contracept Obstet Gynecol 2020;9:3326-9. 